\title{
ESTUDO SÔBRE O CASAMENTO COM SEPARAÇÃO DE BENS NO DIREITO COMPARADO
}

\author{
J. Lamartine Corrêa de Oliveira \\ Professor Substituto da Faculdade de \\ Direito da Universidade do Paraná
}

a) Separação total.

I. O Direito Positivo brasileiro.

II. O Direito estrangeiro.

b) Separação parcial.

I. O Direito Positivo brasileiro.

II. O Direito estrangeiro.

c) O quadro histórico-social.

\section{a) SEPARAÇÃO TOTAL}

I. O Direito Positivo brasileiro

Caracteriza-se tal regime entre nós, define Espínola (1), pela "posse e administração exclusiva, que exerce cada cônjuge, de todos os seus bens, móveis ou imóveis, que tenha ao casar, ou adquira depois, por qualquer título, podendo livremente dispor dos bens móveis".

O princípio da livre administração dos seus bens próprios pela mulher, consagrado pelo art. 276 do Código Civil Brasileiro, predomina nesse regime, que entre nós é convencional, só podendo ser estabelecido pela vontade livre das partes.

Entretanto, a forte tendência comunitarista de nosso direito cria restrições ao regime de separação, apesar da livre

(1) - Eduardo Espínola, "A Família no Direito Civil Brasileiro", Gazeta Judiciária Editôra S.A., Rio, 1954, pág. 344. 
convenção das partes. Os mais típicos exemplos são as disposições dos arts. 235, I, e 242, II, de nosso Código Civil, por fôrça das quais, seja qual fôr o regime de bens, é necessário, para que possa um dos cônjuges alienar bens imóveis, o consentimento do outro. Isto explica, aliás, a parte final da definição de Espínola, definição calcada no Direito Positivo pátrio, e que por isso mesmo, fala em livre disposição apenas dos bens móveis.

Por outro lado, o desfavor em que é tida a separação de bens em nosso regime aparece nos casos de separação legal criados pelo § único do art. 258 do Cód. Civil, os quais possuem caráter a um tempo de providência preventiva e de cláusula penal contra casamentos presumìvelmente contraídos sem a necessária madureza de consentimento. É o caso, v. g., dos noivos idosos, dos muito jovens, ou dos que se casaram com infração de algum dos impedimentos impedientes. No que diz respeito a êstes últimos, aliás, é a separação de bens a sanção específica para desobediência da norma não aparelhada de sanções de nulidade. Ressalta claro o pensamento de nosso Código: nos casamentos totalmente normais, contraídos sem nenhuma motivação subalterna e com o consentimento pleno, maduro, das partes, e o ânimo definitivo de uma união total de duas vidas (tal como pressupõe normalmente o Direito Civil, a fortiori num regime de indissolubilidade matrimonial) o regime que guarda plena coerênicia com a lógica do sistema e a índole da própria vida, é o da comunhão. Indisfarçável o caráter de penalidade, de precaução suspeitosa, que empresta o Código a tais casos de separação legal de bens. Mais indisfarçável ainda êsse caráter nos próprios hábitos sociais, no caso por exemplo de separação de bens imposta pelo pai da noiva.

Finalmente, a constante tendência de nosso direito a restringir a separação total dos bens, encarando-a como regime excepcional e, nos casos comuns, de separação convencional, apenas tolerável, transparece no art. 259 do Código, o qual preceitua que, no silêncio do pacto ante-nupcial, comunicamse os bens adquiridos na constância do casamento, sendo convencional a separação. O que significa, por outras palavras, ser necessária cláusula expressa em sentido contrário, no pacto ante-nupcial, sob pena de transformar-se a separação total 
que as partes pretenderam criar em mera comunhão dos adquiridos ou separação parcial, por fôrça da norma supletiva do art. 259.

No regime da separação de bens, parte-se do princípio de que os bens dos dois cônjuges deve manter-se totalmente independentes. Mas há sempre um fato diante do qual esbarra êsse princípio quìmicamente puro, e que cria um problema a requerer solução: há despesas e encargos que derivam do próprio estabelecimento da sociedade conjugal, seja em virtude do sustento do lar, seja por causa da prole. São despesas e encargos que não dizem respeito nem a um nem a outro dos cônjuges, particularmente. A solução da lei brasileira estabelece que, na falta de estipulação expressa em contrário no contrato ante-nupcial, a mulher é obrigada a contribuir para as despesas do casal, com os rendimentos de seus bens, na proporção de seu valor, relativamente aos do marido (Código Civil, art. 277).

Cumpre lembrar, finalmente, que, entre nós, aplica-se à separação de bens o princípio da imutabilidade, na constância do casamento, do regime matrimonial de bens, princípio aliás vigente na maioria dos países.

\section{O Direito estrangeiro.}

Como no Brasil, em Portugal o regime legal é o da comunhão universal de bens, admitindo-se entretanto, como entre nós, o estabelecimento do regime de separação por via convencional. Existem, porém, casos especiais de separação legal. Lembre-se por exemplo, o do casamento contraído in artículo mortis.

Além disso, existe no Direito português uma forma de separação judicial, requerida pela mulher contra o marido como instituição de ordem pública criada para proteger a mulher contra os desmandos do marido na administração dos bens do casal. Trata-se de separação judicial, nula se feita amigàvelmente e revogável posteriormente por acôrdo dos cônjuges. (Código Civil português, art. 1219 e segs.). Existia tal providência no primitivo projeto de Código Civil brasileiro ${ }^{(2)}$. Na atual legislação brasileira, as medidas cabíveis, de efeitos práticos semelhantes, seriam, principalmente, a rei-

(2) - Clóvis Bevilaqua, "Direito de Famillia", edição de 1938, pág. 218. 
vindicação pela mulher dos bens doados pelo marido à concubina, e a interdição do marido por prodigalidade. Semelhantes ao instituto português, os do Código chileno (art. 155) e colombiano.

Mais fortes ainda que as do Direito brasileiro são as restrições criadas pelo Direito português ao regime da separação de bens. Em Portugal, no regime da separação absoluta de bens, não tem a mulher a livre administração de seus bens próprios.

Roguin lembra que o regime da separação de bens, no estado puro, é o mais simples de todos, pois consiste numa independência absoluta dos dois esposos quanto a seus bens e obrigações. Espínola, comentando tal afirmação, lembra que, em tese, no regime da separação, as relações de conteúdo econômico para com terceiros conservam-se as mesmas do tempo de solteiros (3). E Savatier, com a sua habitual mordacidade, afirma-nos que "a separação de bens é menos um regime matrimonial que uma ausência de regime matrimonial. O próprio de todo regime matrimonial é, com efeito, casar os bens para completar o casamento das pessoas, enquanto que a separação de bens, é ao contrário, o princípio da independência das fortunas, e, pois, a própria negação de um regime matrimonial" (4).

É que o simplismo da construção teórica da separação de bens, como tantos outros institutos do Direito individualista representa uma tentativa de construção de um sistema de lógica perfeita, esquecido porém de que o Direito não tem fim em si, mas fim de regulação da vida humana em sociedade. No caso, o simplismo da construção teórica que estudamos parece esquecer a realidade do mundo dos fatos: o casamento operou uma completa mudança na vida das duas pessoas, mudança que não pode ser ignorada, regulando-se tudo como se casamento não existisse e as partes continuassem solteiras. A vida encarrega-se de propor um problema aos juristas: o problema das despesas comuns do casal no casamento com separação de bens. Diante dêle, dividem-se as soluções legais.

Vimos a solução brasileira, e a portuguêsa, que se enqua-

(4) - Réné Savatier, "Le Droit, l'amour et la liberté", Paris, 1937, pág. 72. 
dram no sistema de obrigar a mulher proporcionalmente a seus bens. É também a solução da lei francesa de 1942 que, modificando o Código Civil, preceituou que os dois contribuem "en proportion de leurs facultées respectives". Outras soluções são: a de atribuir exclusivamente ao marido a obrigação de prover às despesas da família (Direito inglês, vários Estados dos E.U.A., Direito muçulmano); imposição ao marido em primeiro lugar e à mulher de forma como que subsidiária (Alemanha e, de certo modo, o art. 246 do Código suíço - "le mari peut exiger que la femme contribue dans une forme équitable aux charges du mariage"); e, finalmente, a solução tradicional franco-italiana, a solução do Código Napoleão, segundo a qual a mulher deveria contribuir, na ausência de convenção, com a têrça parte de suas rendas, espécie de taxa que pagava, diz Savatier, a seu marido, como sua pensionista pelo fato de dar-lhe êle alimento, roupa, sustento (5) (Código Napoleão, art. 214).

O regime da separação de bens é o regime legal na Itália, onde, aliás, não é permitida a estipulação por convenção do regime da comunhão universal, regime proibido pelo sistema italiano. É também a separação o regime legal na Inglaterra, e em vários Estados dos E.U.A..

Sôbre a Inglaterra, aliás, convém explicar: dado o caráter de elasticidade que confere ao Direito da Grã-Bretanha sua índole jurisprudencial, a jurisprudência tem gradativamente imposto limitações ao princípio segundo o qual o sistema legal é o da separação. Em trabalho por nós consultado, citam-se vários casos judiciários que são disso indício, como o caso Rimmer v. Rimmer, em que a casa conjugal, propriedade do marido (comprada em seu nome) mas com contribuições desiguais dos dois cônjuges, vendida quando de sua separação, teve o produto de sua venda dividido em partes iguais entre os dois cônjuges por decisão do Tribunal. Há então tôda uma série de decisões judiciárias que indicam uma evolução comunitarista por via jurisprudencial, no Direito inglês (5-A).

(5) - R. Savatier, op. cit., pág. 74.

(5-A) - "Le régime matrimonial légal dans les législations contemporaines", trabalho do "Institut de Droit Comparé de l'Université de Paris", feito sob a direção de André Rouast e a colaboração de Jacques Bernard Herzog e Imre Zajtay, “Éditions de l'Épargne", Paris, capítulo “Angleterre", de autoria do prof. M.C.J. Hamson, págs. 37, 40 e 41, especialmente. 
É ainda, em um certo sentido, o regime legal na República Federal da Alemanha. Dizemos em certo sentido, porque a rigor, não existe mais na Alemanha (ou não existe ainda), pelo menos na Alemanha Ocidental, texto de lei disciplinando o regime matrimonial de bens que deve prevalecer no silêncio dos nubentes. A jurisprudência fixou, porém, normas a respeito. Isso, tendo-se em vistas que as normas do B.G.B. sôbre a matéria são consideradas unânimemente abrogadas, quer na Alemanha Ocidental, quer na Oriental. A inexistência de texto escrito de lei tem sido, na Alemanha Ocidental, sanada pela jurisprudência. E esta tem entendido ser 0 regime da separação de bens o que deve vigorar em caso de ausência de estipulação em contrário. Corrente jurisprudencial minoritária tem entendido, entretanto, dever prevalecer no silêncio das partes o regime da comunhão dos adquiridos, tal como regulado pelos $\S \S 1519$ e seguintes do B.G.B., derrogadas porém as normas previstas para tal regime pelo $\mathrm{B}$. G.B. que infrinjam o princípio da absoluta igualdade entre marido e mulher. Os tribunais e juízes partidários da corrente majoritária baseiam-se na simplicidade e clareza do regime de absoluta separação, e no fato de que a igualdade entre os esposos por êle realizada, ao menos do ponto de vista formal, é mais perfeita.

Lembremos ainda que, na Alemanha, pacto sôbre regime matrimonial (contrato de casamento) pode ser feito em qualquer época da vida dos cônjuges e não apenas em pacto antenupcial e que, portanto, não tem acolhida no sistema alemão, o princípio da imutabilidade do regime de bens do casamento, permanecendo em pleno vigor o princípio da mutabilidade, estabelecido pelo $\S 1432$ do B.G.B. ${ }^{(5-B)}$.

Previsto, entretanto, com caráter convencional, surge o regime da separação de bens na França, Suíça, na Espanha, no Chile, no México e em outros países hispano-americanos. Como em Portugal e no Brasil. Há, entretanto, na maioria dessas legislações, casos em que a lei impõe obrigatòriamente o regime da separação de bens.

Na França, podem os cônjuges declarar no pacto ante-

(5-B) - "Le régime..." trab. cit., capítulo "Allemagne", da autoria do prơ.
Hans Dolle, págs. 29 a 31 . 
nupcial que se casam sem comunhão (nesse caso, não tem a mulher o direito de administrar seus próprios bens, nem de perceber-lhes os frutos) ou separados de bens, caso em que, ex-vi do art. 1536, cfr. a redação dada pela lei de 22-9-1942, "la femme conserve l'administration, la jouissance et la libre disposition de ses biens".

\section{b) SEPARAÇÃO PARCIAL}

\section{O Direito Positivo brasileiro.}

Sob êsse nome, de separação parcial, que foi consagrado por Lafayette, o qual entendia que em tal regime o sinal característico é a separação, regra geral, destacando-se entretanto, para uso e gôzo comum do casal, alguns bens, estudaremos o regime que nosso Código denomina regime da comunhão parcial. Na realidade, legislações há, como a portuguêsa, que prevêem, como regimes distintos, a comunhão de adquiridos e a separação parcial. Trata-se entretanto de regimes pràticamente idênticos, como veremos infra.

Na verdade, o regime que ora estudamos é a um tempo de comunhão parcial e de separação parcial, por isso mesmo que parte dos bens são colocados sob a propriedade comum do casal, enquanto que outra parte permanece como bens próprios de cada um dos cônjuges, bens separados, apartados da comunhão. Cientìficamente, parece-nos mais feliz a denominação de nosso Código - comunhão parcial —, já que em tal regime a comunhão é regra, à qual fazem exceção certas e determinadas categorias de bens. Por amor, porém, à sistemática dêste trabalho, adotaremos a terminologia de Lafayette.

Entre nós, o regime que o Código denomina comunhão parcial só pode ser convencionado em pacto ante-nupcial, mediante o uso da expressão "comunhão parcial" ou equivalente.

Uma vez estabelecido por tal via, excluir-se-ão da comunhão:

a) os bens que cada um dos cônjuges possuir no momento do casamento. Código Civil, art. 269, I. A celebração do matrimônio funciona portanto, permita-se a analogia co- 
uma lei nova que determinasse a comunhão dos bens, entre as pessoas casadas, respeitando-se, entretanto, a propriedade (separada dos bens adquiridos antes do casamento.

b) os bens que, na vigência da sociedade conjugal, re ceber qualquer dêles por doação ou sucessão. Ainda Código Civil, art. 269,I.

c) os adquiridos com valores que pertençam exclusivamente a um dos cônjuges, em subrogação de seus bens particulares. C. Civ., art. 269, II.

d) as obrigações anteriores ao casamento. C. Civ., art. 270 , I. No regime da comunhão universal, comunicam-se as dívidas anteriores ao casamento, quando provenientes de despesas para o casamento, ou na proporção do proveito comum (art. 263, VII), o que não acontece no regime que ora estudamos.

e) as obrigações provenientes de atos ilícitos. C. Civ., art. 270, II. Neste ponto, é idêntica a situação em matéria de comunhão universal.

Incluem-se, porém, na comunhão:

a) os bens adquiridos na constância da sociedade conjugal, a título oneroso, ainda que só em nome de um dos cônjuges, excluídos os adquiridos na forma do art. 269, II. C. Civ., art. 271 , I.

b) os adquiridos por fato eventual, com ou sem o concurso de trabalho ou despesa anterior. C. Civ., art. 271, II. Neste ponto, uma indagação comumente aflora: os acessórios de bens particulares, se adquiridos por fato eventual ou fortuito, são comuns ou particulares? Divide-se a doutrina neste ponto entre os que, como Pontes de Miranda, entendem que os acessórios, em tal caso, seguem a sorte do principal, sendo portanto bens particulares, a não ser que se trate de frutos ou benfeitorias, caso em que prevalecerão as exceções que a lei expressamente quis criar - art. 271, IV, V e VI e os que, como Clóvis e Espínola entendem que a intenção da lei foi incluir na comunhão tudo aquilo (o texto não excetua) que, na constância do casamento, fôr adquirido por fato eventual. Milita em favor dos últimos o fato de que, em tal regime, em face da lei brasileira, regra geral é a comunhão. 
c) os adquiridos por doação, herança ou legado, em favor de ambos os cônjuges. C. Civ., art. 271, III.

d) as benfeitorias em bens particulares de cada cônjuge. C. Civ., art. 271, IV.

e) os frutos dos bens comuns ou dos particulares de cada um dos cônjuges. C. Civ., art. 271, V.

f) os frutos civis do trabalho ou indústria de cada cônjuge, ou de ambos. Cód. Civ., art. 271, VI.

Por fôrça do art. 272, "são incomunicáveis os bens cuja aquisição tiver por título uma causa anterior ao casamento".

$\mathrm{E}$ o art. 273 determina deverem os nubentes, no pacto ante-nupcial, arrolar os bens móveis que cada um dêles possui no momento para que tais bens sejam excluídos da comunhão. O mesmo art., supletivamente, presume, comuns os móveis não relacionados. Tal presunção é absoluta, juris et de jure. Ao contrário do Direito francês em que, desde a lei de 29-4-1942, é admitida a prova em contrário, tendo sido transformada, portanto, a presunção do Cód. Napoleão, de conteúdo idêntico à nossa, em presunção juris tantum.

Por fôrça do art. 274, é o marido o administrador dos bens do casal, quer dos comuns, quer dos seus próprios, quer dos próprios da mulher. Admite-se, entretanto, no pacto antenupcial, reserve a mulher bens próprios seus, desde que móveis, para sua livre administração e disposição.

$\mathrm{O}$ art. 246 permite à mulher livremente dispor os bens que adquira no exercício de profissão lucrativa.

As dívidas contraídas pelo marido obrigam os bens comuns e, subsidiàriamente, em caso de insuficiência dos comuns, os bens particulares de cada um dos cônjuges, na razão do proveito que cada um houver tido. C. Civ., art. 274. Será a mesma a solução quanto às dívidas contraídas pela mulher no caso de dívidas resultantes de atos autorizados pelo marido, expressa ou presumidamente ou de atos que independam de autorização marital. C. Civ., art. 275.

Dissolve-se a comunhão parcial, convertendo-se, portanto, em separação total, do mesmo modo que a comunhão universal, pela morte, pela sentença que anula o casamento, 
quando putativo (isto é: quando um dos cônjuges, ao menos, estava de boa-fé; nos outros casos de anulação e nos de nulidade, não haverá dissolução de comunhão, mas tudo se fará, antes, como nunca tendo havido comunhão alguma), e pelo desquite.

\section{O Direito estrangeiro.}

O Direito português, no qual, tal como entre nós, o regime legal é o da comunhão universal, prevê, com caráter convencional, o regime da "comunhão dos adquiridos", semelhante à nossa "comunhão parcial e, ao mesmo tempo, o regime da "simples separação", o qual, como elucida Cunha Gonçalves (6) "pouco se diferença, pràticamente, do da comunhão de adquiridos, já porque o art. 1125 do mesmo código dispõe que não se haverá por excluída a comunhão dos adquiridos, já porque o art. 1126 dispõe que a êsse regime são aplicáveis os arts. 1130 a 1132 , que regulam o regime da comunhão de adquiridos". No sistema português, ex-vi, do art. 1104, a mulher não pode privar o marido da administração dos bens do casal, mas pode reservar para si "a título de alfinetes, uma parte da renda de seus bens que não exceda. da têrça parte dos rendimentos líquidos".

Bem aparentado a tal regime é o do Direito francês, $d a$ comunhão dos móveis e dos adquiridos, que, entretanto, é legal e prevalece no silêncio das partes, na ausência de pacto ante-nupcial, e em que a comunhão é constituída: a) por todos os móveis que os cônjuges possuirem no dia do casamento e pelos que adquirirem depois, ainda que por meação ou doação; b) por todos os frutos e rendimentos de bens pertencentes aos cônjuges antes do casamento e por todos os que, por qualquer título, venham a pertencer-lhes; c) todos os imóveis adquiridos depois de casados. Ao marido incumbe a administração dos bens da comunhão, podendo dêles dispor sem o concurso da mulher, exceto se a título gratuito. Administra também os bens da mulher que, só por mandato geral expresso ou tácito, pode participar da administração dos bens comuns. Pode a mulher dispor de sua parte na comunhão por disposição de última vontade. Tem, contra o ma-

(6) - Luiz da Cunha Gonçalves, "Princípios de Direito Civil luso-brasileiro", ed. Max Limonad, São Paulo, 1951, vol. III, pág. 1240. 
rido, os remédios seguintes: a) separação judicial de seus bens; b) a faculdade de renunciar à comunhão; c) a reserva dos bens adquiridos no exercício de sua profissão (caso renuncie à comunhão); d) preferência no caso de partilha do ativo; e) hipoteca legal sôbre os bens do marido.

Apesar de ser tal regime de comunhão de móveis, Clóvis (7) lembra quatro categorias de móveis que não entram na comunhão: 1. a das pensões, dotações, ordenados, aposentadorias; 2. os móveis que provêm dos imóveis próprios, sem que sejam frutos; 3 . os que substituem os bens próprios; 4. os dados ou legados a um dos cônjuges sob a cláusula de incomunicabilidade. Quanto aos imóveis é ainda Clóvis (s) quem enumera, excluem-se da comunhão: os possuídos antes do casamento, os que são adquiridos a título gratuito (sucessão ou doação) os cedidos por ascendente a um dos cônjuges em pagamento dos que lhe deve ou para pagamento das dívidas do doador, os permutados por bens próprios e os retirados da indivisão (art. 1404).

É, em linhas gerais, o regime da Bélgica, e da província canadense de Quebec. Bem como o do Estado da Louisiana, nos E.U.A. (8-A).

Outra forma de comunhão parcial é a chamada sociedade legal ou "sociedad de gananciales", regime em que cada cônjuge conserva a propriedade dos bens que antes do casamento possuía bem como os que depois vier a adquirir por doação ou sucessão, comunicando-se, entretanto, os adquiridos a título oneroso na constância do casamento, o produto da indústria de cada cônjuge, os rendimentos dessas aquisições e dos bens próprios, e as aquisições a título oneroso. A administração é do marido. Não estão incluídos, portanto, os móveis, em geral, como no sistema francês.

É o sistema legal espanhol. Forma-se com o casamento uma categoria de "bienes comunes o ganaciales", destinados a ulterior divisão por metade quando da dissolução da socie-

(7) - Clóvis Bevilaqua, op. cit., ed. cit., pág. 219.

(8) - Idem, ibidem.

(8-A) - "Le régime...", trab. cit., capítulos "Belgique", da autoria dos professôres Claude Renard e Paul Graulich, pág. 6", “Canadá-La province de Quebec", da autoria do prof. Pierre Azard, pág. 85 e "Etats-Unis-La Louisiane", da autoria de John H. Tucker, pág. 157. 
dade ou do vínculo conjugal e administrados, na constância do matrimônio pelo marido (Cód. espanhol, art. 1392 e arts. 1412 e segs.).

É também o sistema espanhol o adotado na Argentina como regime legal, na Colômbia, no Uruguai, na Venezuela (Argent.: Lei 11.357; Cód. Colombiano, art. 1774 ("sociedad conyugal"), Cód. do Uruguai, art. 1938, al. 2 - "asociación conyugal"; Cód. da Venezuela, de 1942 - arts. 148, 149 e 150 - "comunidad de los bienes gananciales). Na Venezuela, aplicam-se supletivamente as regras do contrato de sociedade (art. 150) e a administração do marido não abrange os bens adquiridos por indústria, profissão ou trabalho da mulher, assim como os frutos que tais bens produzem, os quais são administrados pela mulher.

No Chile é regime legal o de "sociedad de bienes" ou "separación parcial", semelhante ao regime espanhol. Há importantes peculiaridades: à mulher pertencem, como bens separados, os produtos de seu trabalho. E o regime de bens não é imutável, podendo a separação parcial ser substituída pela separação total, na constância do casamento, por livre acôrdo dos cônjuges (lei 7.612, de 21 de outubro de 1934).

Também no México é regime legal o de separação parcial, sob o nome de "sociedad conyugal", admitindo-se apenas convenção em contrário para escolha do regime de separação total de bens (Código de 1928).

Interessante notar que a doutrina francesa atualmente inclina-se por uma modificação do regime légal de bens no casamento, abolindo-se a comunhão de móveis e adquiridos do sistema do Código e substituindo-a por uma simples comunhão de adquiridos ${ }^{(9)}$.

Sob o nome de comunhão diferida tem sido estudada uma forma de separação total, com administração separada, responsabilidade por dívidas e contribuição de ambos os cônjuges para as despesas do lar, efetuando-se entretanto, ao dissolver-se a união conjugal, uma massa comum, em que entram todos os adquiridos, e que é partilhada entre os cônjuges ou seus herdeiros. Tal regime, que é o da Suécia, da

(9) - Espínola, op. cit., pág. 338, nota (35). 
Finlândia, do projeto do Senado belga de 1949, etc., aproximase muito mais da separação absoluta. Diferencia-se desta apenas no momento da dissolução do casamento.

Pelo regime suíço da união dos bens, acham-se os bens reunidos apenas para o efeito de serem administrados pelo marido. Excluem-se da administração marital os bens reservados da mulher. Lembra Clóvis (10): "os frutos pertencem ao marido e, por morte dêle, dois têrços dos lucros existentes excluindo-se de tal disposição os bens reservados da mulher (arts. 194-214). Não há comunhão neste regime, a não ser ao dissolver-se a sociedade conjugal". Assim é que, em tal regime, cada um dos cônjuges continua proprietário dos bens com que entrou para a união de bens, devolvendo-se aos herdeiros da mulher, por morte dela, os bens com que contribuiu, reservados os direitos sucessórios do marido (art. 212) e recebendo a mulher, por morte do marido, dos herdeiros dêle, os bens a que tem direito, podendo pedir indenização pelos não representados (art. 213).

O regime da comunhão dos adquiridos é a única forma de comunhão convencional admitida pela lei italiana e em verdadeira comunhão de adquiridos, pela doutrina da sociedade de fato, tem a jurisprudência brasileira transformado os casamentos de italianos casados na Itália pelo regime da separação de bens, vindos para o Brasil no início da vida, tendo aqui vivido todo o resto de sua existência terrena. Evita-se, assim, na sucessão mortis-causa, o prejuízo da viúva, co-responsável pelo sucesso dás economias do casal.

É ainda o regime legal da Hungria, desde o decreto-lei 23/1952, e o da União Soviética (10-A).

\section{c) O QUADRO HISTÓRICO-SOCIAL}

Entre os germanos teve o seu florescimento o regime da comunhão de bens. Entretanto, foi o direito luso-brasileiro que lhe deu maior acolhida e recepção em tempos atuais, vivificando-o e dando-lhe um sentido novo a que não é estra-

(10) - Clóvis Bevilaqua, "Comentários ao Código Civil”, 11.a ediçăo, Rio, 1956, vol. II, pág. 147, comentário ao art. 269, parte de "Legisl. comparada".

(10-A) - "Le régime...", trab. cit., capítulos "Hongrie", da autoria de Imre Zajtay, e "U.R.S.S.", da autoria do dr. Michel Fridieff (código da R.S.F.S.R., art. 10). 
nho o cristianismo. (Como regime legal, conhecemos a comunhão universal, além do caso de Portugal e Brasil, na Dinamarca e na Holanda; admitem-no como sistema permitido por convenção das partes a maioria dos países. Exceção flagrante é o caso da Itália, em que o regime denominado pelo Código de 1942 de comunhão universal nada mais é do que uma comunhão de adquiridos, sendo inadmissível aos olhos da lei italiana a nossa comunhão universal).

Por outro lado, é fora de dúvida que o regime da separação de bens vai buscar suas origens no individualismo. É a concentração de grandes fortunas que ensejará as primeiras preocupações com a consolidação jurídica de um regime de separação de bens. Em Portugal, surgem os chamados casamentos morganáticos, com a "morganheira", com a exclusão da comunhão. E Savatier, citando Bonnecase, lembra a mentalidade das populações meridionais da França, com o "sentimento dos pais da noiva, organizando com antecedência, contra seu genro, a defesa constante e atenta dos bens que dão ou deixarão à filha" (11). Assume, no decorrer dos tempos, as características de instrumento de defesa da concentração da propriedade imobiliária em mãos de determinadas famílias e o fenômeno histórico da ascensão da burguesia, do predomínio do liberalismo individualista, não apenas como filosofia dominante nas instituições político-sociais, mas como verdadeiro prisma dominante nos costumes de várias gerações, deu fôrça e possibilidade à expansão do regime de separação de bens.

O Código Napoleão, exemplo clássico de individualismo jurídico, deu-lhe uma construção sóbria e bela do ponto de vista formal, mas que se ressente gravemente, quanto ao conteúdo, do pecado individualista. Uma sociedade que deixara de crer no caráter sacramental do matrimônio e que começava a efetuar a separação entre amor e matrimônio, e em que o divórcio começava a penetrar com fôrça de hábito social, forneceu a base humana para a expansão do instituto.

Savatier fez, com precisão e elegância (12), o "processus" do instituto separatista. Assinala a lenta evolução do regime da separação em direito francês, mostrando o sistema do 1/3

(11) - R. Savatier, "Le Droit, l'amour et la liberté", ed. cit., pág. 71.

(12) - Ver nota seguinte. 
dado pela mulher ao marido, a título de pagamento de pensão, a necessidade, para que o sistema funcione, de prestação rigorosa de contas de um ao outro (da mulher ao marido, quanto às despesas do lar, já que ela as faz com dinheiro dêle e que seus $2 / 3$ são em princípio reservados a seus próprios luxos e despesas pessoais). Se tais contas forem prestadas, lembra o mestre francês, "o individualismo das fortunas, os direitos sagrados da propriedade de cada um, serão plenamente salvaguardados; apenas, êsse casal contábil terá poucas possibilidades de ser um casal apaixonado!" (13). De fato, entretanto, na maioria dos casos, o sistema clássico do Código Napoleão teve como conseqüência um estado de coisas em que, impossível separar as contas de cada um, terminava por aproveitar sòmente ao marido a prosperidade do casal.

Foram introduzidas aos poucos modificações jurisprudenciais que vieram beneficiar a mulher, evitando fôsse ela espoliada pela má administração de seu marido, que estabeleceram restrições à independência dos patrimônios, em atenção aos direitos dos credores, fàcilmente burláveis pelo sistema da passagem aparente de bens do patrimônio do cônjuge endividado para o do outro. O primeiro após-guerra, em 1918, produziu na França uma nova corrida ao casamento com separação de bens, coincidindo com os movimentos feministas e com a mentalidade reinante na geração mais jovem de que era necessário, apesar do casamento e no casamento, conservar cada um dos dois cônjuges o máximo de independência e liberdade. E novo dilema se forma: ou os dois se entendem ou não se entendem. Se não se entendem, crêem que foi ótimo o regime de separação de bens. Mas aí não existe mais um casamento vivo e normal e sim um casamento doente, que poderá desaguar em divórcio ou no chamado "casamento frio". Se se entendem, a vida vai aos poucos mudando o regime, improvisando-se uma bôlsa comum para as despesas comuns, e criando-se um jôgo de esconde-esconde, de patrimônio a patrimônio, para a fraude aos credores. Os problemas sucessórios são sérios, sobretudo quando um dos cônjuges morre $a b$ intestato, sem filhos, e o outro entra em luta com a família do falecido.

Na pior das hipóteses, o regime da separação de bens significou e acentuou um estado de reservas e desconfianças de 
um dos cônjuges para com o outro, incompatível com o ideal do matrimônio. Mas, melhor, - fale Savatier pela última vez, aparece, contràriamente a tôdas as veleidades de individualismo, a unidade profunda do casal. A fôrça das coisas a samento, declarando-se casados com separação de bens" (14). restabeleceu, por intermédio dos tribunais; a despeito de tudo o que os cônjuges tenham inserido em seu contrato de ca-

Que fazer, entretanto, quando uma sociedade profundamente marcada pela ação desumanizante do individualismo de várias gerações, agravado tudo isso pelos indisfarçáveis problemas criados pela agitada e dramática convivência humana de nossos dias, coloca dificuldades sérias, que a comunhão universal de bens só faria agravar, no caso de certos casamentos? Daí, a função intermédia e equilibradora do casamento com comunhão parcial em que, considerado inviável para certos casos excepcionais o ideal da comunhão universal, não se aceita entretanto o sistema separatista total, em suas linhas mais utópicas e contrárias à própria natureza da instituição conjugal. Êste último regime deve continuar sendo o regime dos casos extremos, o mal necessário, nada mais do que isto.

(13) - Savatier, op. cit., pág. 78. As citaçōes e o raciocinio desenvolvido desde o ponto correspondente à nota anterior bem como a própria citação da nota (12) têm por base Savatier, op. cit., págs. 78 e anteriores, imediatamente. 